\title{
Pragmatic function of terminology and the dual nature of economic concepts
}

\author{
Pavel Korobka* \\ Don State Technical University, 344000, Rostov-on-Don, Russia
}

\begin{abstract}
The paper presents a new way of considering the pragmatic function of economic terms based on the understanding of the concepts rendered by them as having dual - descriptive and simultaneously prescriptive character, prescription being linguistically realized as a pragmatic function. With this in mind a brief survey of philosophical works giving axiological analysis of scientific definitions characteristic of economics as a social science is made. It is shown that a set ofeconomic terms specific for a particular school of thought or a socio-economic situation do not only or sometimes even so much reflect actual economic reality as give the latter a direction through the pragmatic function they are meant to fulfill. The pragmatic aspect of the terms' meaning is realized at different levels having linguistic relevance, its exponents being incorporated into an intricate system of interrelations and associations. Thus the paper offers an approach along the lines of which - if applied to further investigations - there may be gained a deeper insight into the idiosyncratic processes underlying the cognitive and regulatory functions of the terminology belonging to the sphere of economics.
\end{abstract}

\section{Introduction}

Economics and the terminology designating its various and complex concepts have long been of special interest not only for the economists but also for scholars working in other social and natural sciences, humanities, and the arts.In linguistics terminology in general and economic terminology in particular is commonly considered from the point of view of the well-known formal and semantic requirements to be met by the units of the given layer. Investigating the issues related to the methodology of translating scientific terms E.V. Krasnova points out that being an integral part of scientific-technical style terminology plays a key role in ensuring "a strict precision of the functioning of all its elements"[1,2].

However economics occupies a special place among other social sciences in so far as its theories, conceptions and approaches are laid at the grounds of policies pursued by governments to solve problems arising in different economies and have, therefore, a strong bearing on the life of societies which is evident from the abundance of media devoted to discussing economic issues or even consulting on certain questions relating to finance, taxation, exchange rates and the like. Thus economic questions go far beyond the realms of economics, cease to be solely experts' concern and become the subject of public discussion. And it is through economic terms that corresponding concepts are expressed. In these conditions pragmatic function of the terms often comes to the fore. The pragmatic function 
being here understood as the ability of a linguistic sign to evoke a particular state of mind, mood or action on the part of the recipient is heavily dependent on a set of characteristics such as the way by which denotational meaning is related to the meanings of morphemes making up the formal aspect of the term or its motivation, the peculiarities of the many and diverse interrelations existing between the concept expressed and the entire system of other categories peculiar for a given economic theory or conception, the degree and type of idiomaticity.

On the other hand similar issues - the specific character of scientific definitions, in particular, their dual descriptive-prescriptive function, the subdivision of categories into absolute and comparative notions, the types of scientific rationality, the criteria for classifying the fields of human activity aimed at gaining knowledge into natural, formal and social sciences, humanities, and the arts have been considered in philosophyfrom the point of view of the theory of values - axiology [3]. A.A. Ivin stresses the importance of making clear distinction between the statements establishing the congruence of thought with its object versus the congruence of an object with the thought of it. The opposition of these two types of statements - descriptive and prescriptive - may be called classical as it goes back to the times of antiquity. Being independent of any concrete properties of objects matching the thought such understanding of values may be called absolute. Real utterances of speech however can rarely be referred to as purely descriptive or prescriptive. More often than not they simultaneously perform the two functions - those of describing and evaluating. In accordance with the opposition between the statements characterized in terms of "true / false" and the statements being evaluated in terms of "good / bad" all definitions fall into two broad categories - real definitions and nominal definitions or conventions respectively. Prescriptive aspect of definitions may be expressed explicitly or implicitly. One of the types of definitions containing implicit values is convention. Conventions may render new scientific concepts, however, of much greater interest turn out to be conventions delimitating or widening the already existing notions as well as conventions identifying different sets of features. A system of nominal definitions or conventions included in a scientific theory belong to the theory's internal values and constitute the structure of the theory. Aside from internal values there are external values of a theory. External values are diverse and heterogeneous. They include principles, rules, patterns, norms, evaluations the effects of which have either a direct or indirect bearance both on the formation of a theory and its further development. Of special interest are the values determining the basic traits of the style of thinking. By the style of thinking there may be understood the way of thinking specific for a particular science in a certain period of its development or in a broader sense - the general way of theoretical reasoning characteristic of an entire epoch. The latter has to do with all the forms of theorizing characteristic of a particular historical period and constituting a complex system of most general principles, patterns, forms and categories of theoretical representation of the world. The way of formulating judgments in concrete sciences should be in consistency with the manner of reasoning adopted both in a given field of knowledge and should be in compliance with the style of theorizing specific for a particular epoch. The style of reasoning setting out the standards of theoretical activity performs therefore regulatory function. The relationship between the style of reasoning and a theory is a typical value relationship. The extent to which a theory is consistent with the adopted style of reasoning determines the theory as "good" or "bad". The style of reasoning on the other hand is the result and inference of the preceding development of science and theoretical thinking. Thus it can simultaneously be defined as descriptive. Of the same descriptive-prescriptive character are the criteria of the theory adequacy and regulatory principles of scientific research. The regulatory principles function as "heuristic pointers" helping to formulate and realize a research program as well as prescriptions having to do with making up and evaluating theoretical systems. At the same time they are formed in the 
course of doing practical scientific research and are an attempt to realize the laws of acquiring new knowledge. Hence they perform the function of describing. The comparison of a theory with regulatory principles means matching a "theoretical reality" set out by the theory with some adopted "pattern" thus establishing an evaluative relationship. Economics is defined as a social science inasmuch as it tends to use comparative rather than absolute categories according to the binary opposition "becoming - being" [4].

It is interesting to note that within the general theory of values there is a special theory dealing with values from a utilitarian point of view. The use of the concepts "utility", "commodity" and the like brings it rather close to the categories typically treated in economics [5]. In philosophical studies however values are traditionally considered as axiological aspects of philosophical teachings and are believed to be hierarchically organized [6]. It is commonly stressed that values have a subjective nature and - as skeptically stated by R. Boudon "the validity of values cannot be checked". "We can easily accept neither the view that scientific theories are grounded on principles which we would accept by an ungrounded act of faith, nor the view that they would be ultimately ungrounded". To get out of the Catch 22 situation he sets forth a solution according to which scientific knowledge is attained through the cyclic repetitive moving "from principles to consequences and, in turn, from the consequences to the principles" if the principles prove to agree with empirical data they become part of the theory, if not - they are questioned and rejected. Usually a scientific theory is based on "undemonstrated principles" or "beliefs" or even "acts of faith" serving as starting points of any research and building up a theory [7]. These undemonstrated principles are however essentially similar to what is generally termed as "conventions" and "nominal definitions".

No matter how philosophically abstract and far from the linguistically relevant questions the above considerations might seem they do have a direct connection to the investigation into the content plane and functioning of economic terms. This is evidenced by the interest linguists take in the ways and processes of terms formation and the types of motivation they display. Considering a set of economic terms coined as a result of action of metaphor and metaphor-like processes M.T. Musacchio highlights the importance of looking at economics as a science making an ample use of a variety of mathematical methods and at the same time having much to do with the routine of "everyday experience of economic transactions" thus retaining the status of a social science. The author classifies the whole bulk of metaphorically formed terms into "constitutive", "pedagogical" and "heuristic". As can be seen from the examples and explanations "constitutive metaphors" are those expressing some "change, that is variation taking the form of a pattern or trend", e.g.: "production function", "market equilibrium" which clearly show the mechanistic way of reasoning characteristic of the time they were formed - hence the motivation of the terms proves to be dependent on a broader situational context which in terms of axiology is known as external values of a scientific theory. Another example is the term "growth" the motivation of which implies the comparison of an economy with a living organism. The metaphors "playing a role in teaching and explaining theories" are classified as "pedagogical", e.g.: "circular flow diagram". "Heuristic metaphors" are those "catalyzing thinking" and "propelling thought" - such characteristics are evident of the pragmatic function the terms fulfill. The use of a particular type of metaphor in economics is mostly differentiated according to text type and to a lesser extent according to a language in which the text is created. In reports on economics where constitutive metaphors are mostly used sentiment is expressed "in a highly controlled fashion, i.e. with frequent hedging and down toning". Newspaper articles tend to employ pedagogical metaphors in the context of a more emotionally charged language. Occupying an intermediate position between reports and articles translated texts are characterized by a mixed use of both "constitutive" and 
"pedagogical" metaphors the use of culturally specific metaphors present in the source text being avoided [8].

The review of the works devoted to the study of economic terminology shows that on the one hand the units belonging to the sphere possess characteristics common for scientific terminology in general - accuracy and exhaustiveness of a concept's description, monosemanticity, systematic character, lack of an emotional charge, brevity. On the other hand economic terms serving to convey systemically interrelated concepts come as conventions having dual -descriptive-prescriptive meaning. This meaning duality displays itself in the pragmatic function of the sign which is relevant for communication. There have been quite a large number of investigations intended to reveal the peculiarities of economic terminology through addressing some of its axiological aspects. However the results of such investigations have to be recognized as fragmentary and unsystematic. Hence the aim of this paper is to offer the systemic multi-level approach that would ensure an overall studying of the numerous and complex ties accounting for the pragmatic function of economic terminology.

\section{Materials and Methods}

To reach the objectives of the study presented in this paper it was necessary to make use of special reference literature (mostly dictionaries and encyclopedias) [9-13] as well as academic textbooks and monographs on economics. For the comparison of the encyclopedic definitions of the units belonging to the metalanguage of economics with their linguistic counterparts explanatory dictionaries were used.

In compliance with the aims of the research a set of linguistic methods were used: descriptive, comparative, structural, some procedures pertaining to comparative-historical method.

\section{Results}

Most of the terms used in the classical economic theory coincide in form with the lexical units functioning in everyday speech. Such terms as "land", "labour", "market", "revenue", "price", "commodity", "services", “distribution", "value”, "property", "expenditures", "costs" and the like can stand for both economics concepts [14-16] and notions related to everyday reality. Words of common language may come to denote special concepts and become terms. The reverse holds true as well - terms may enter the sphere of media and through it -return to everyday speech, e.g.: "gross national product", "state property", "private property", "labour productivity", "market production" and the like. Some of such words designate negative phenomena in the economy of a country. For instance, the term "sub-prime debt" was introduced as a reaction to the crisis and was later substituted for another euphemism - "toxic assets"; the shares of financial institutions that became worthless were renamed as "bagels" in the USA: a ring-shaped type of bread resembling the figure zero [17]. From the political-economic discourse in Russia there can be drawn examples such as "social mobility" or "the self-employed". In such cases the pragmatic function of the terms is displayed through the shift of their motivation. With regards to economic problems however it should be mentioned that there seems to be a tendency to raise responsibility questions [18].

Axiological aspect of the economic terminology can also be traced at the level of concepts which constitute economic theories. The evaluative character of economic concepts can be seen and analyzed in the following ways: (1) implicitly - through the relations of one concept to others within the same theoretical construction, (2) quite 
explicitly - through the relations of a concept belonging to one theoretical system to the concepts making up an opposing theory, (3) associatively - when a certain concept being largely outside the scope of the theory is just arbitrarily ascribed to it, (4) synonymically that is the case when two (or even more) forms come to designate the same concept usually with transparent implications due to a specific change in motivation. The first type of relationships can be illustrated by the definition of such common economic concept as "commodity" - "something that is sold for money" - hence "commodity" presupposes the concepts of "trade", "money", "price", etc. - they prove to be complementary in relation to it. The postulate underlying these concepts may be worded as follows: "There should be trade as a way of exchanging commodities" - one of the values of the theory. The second type - dealing with opposing concepts, i.e. having the same plane of expression but differing in contents of the notions - can be exemplified both diachronically and synchronically. In medieval times there were different views on the nature of money but the prevailing belief was that "since money was made of imperishable and precious metal, it could also be used as a store of value, which might allow individuals to accumulate large sums of it" [19]. But from the point of view of contemporary mainstream economics theory "money" came to mean "anything that serves as a medium of exchange, unit of account, and store of value". Though "store of value" is still there, no doubt - the physical form of it now is mostly paper - not silver or gold. Hence "a medium of exchange and unit of account" come to the fore. As for the values oppositions observed at present they seem to be best revealed in a context involving critical review of one economic theory on the part and from the point of view of an economist adherent to another - competing economic conception. Criticizing Marx's economic theory Ph. J. Bernard encloses the word "laws" (the laws of socialism) and even the whole phrase "the laws of the balanced or planned development of a socialist economy" in inverted commas. The inverted commas serve here not only as quotation notes but are clearly indicative of his doubt about the status of the dependency he considers. By "laws" he understands only dependencies described in market economy theories [20]. Nevertheless the former laws have objectively no less grounds to be called so than the latter - both types of laws work but in different conditions. This is a vivid evidence of the fact that any economic conception is an adopted and adhered to system of values. The third - associative type - involves cases when certain concepts (mostly positively evaluated) are made use of for supporting a particular theory or conception.

However they are not among the concepts of a theory. Studying the changes in the usage of economic terms A. Rajewsky points out a number of terms that were in use in prerevolutionary Russia. Among them there are words "charity" and "bona fides" (good faith) [21]. The use of such words in political and economic discourse is aimed to somehow soften the negative psychological effects of an economy's functioning. They turn out to be accompanying and supportive of the major concepts and conceptions laid at the basis of the development of economic policy. Being part of socio-economic life the phenomena denoted by such words do not play a principal role and are therefore termed in this paper as "Concept 0 ". The fourth - synonymic - type of relationships between the concepts and their exponents is conditioned by the tendency of certain terms to gradually become capable of evoking negative feelings on the part of the listener or hearer, e.g. "crisis", "inflation", "economic depression" and the like. The synonyms of the type have received the name of "economic euphemisms" which are deliberate substitutions of an existing word or phrase for a more correct according to the actual economic conditions and the mentality of the speaker. For instance the current complicated economic situation, the expansion of financial crisis, increasing the scale of its detrimental effects and low efficiency of anti-crisis measures stimulates the appearance of euphemistic substitutions in the sphere of economic terminology. The initial term "economic slowdown" has more than once been substituted for "banana", "bad times", "credit crunch", "decline", "downturn", "economic collapse", 
“economic depression”, "stagflation”, “financial meltdown”, "financial storm”, "financial stress", "financial turbulence", "financial turmoil", "liquidity crisis", "recession", "Rword", "slump", "subprime crisis" and the like. The distribution of the types of relationships between terms serving to covey economic concepts is represented in Table 1.

Table 1.The distribution of relationships between terminologically expressed economic theory concepts

\begin{tabular}{|c|l|l|}
\hline Relationship & & \\
\hline Complementary & Concept 1 of Theory 1 & Concept 2 of Theory 1 \\
\hline Opposing & Concept 1 of Theory 1 & Concept 1 of Theory 2 \\
\hline Associative & Concept 1 of Theory 1 & Concept 0 of Theory 2 \\
\hline \multirow{2}{*}{ Synonymic } & Concept 1 of Theory 1 & Concept 1 of Theory 1 \\
\cline { 2 - 3 } & Concept 2 of Theory 2 & Concept 2 of Theory 2 \\
\hline
\end{tabular}

\section{Discussion}

The results of this work allow to build up a procedure of consistent and systematic studying of economic terminology from different angles based on the awareness of the dual descriptive-prescriptive character of scientific terminology in general and economic terms in particular. Bridging the gap between what has been achieved in philosophy and axiology on the one hand and communicative linguistics on the other is likely to yield new important outcomes and gain a deeper insight into such an intricate sphere as the correlation between the peculiarities of terminological definitions, their intrinsic and extrinsic ties and the communicative properties of this lexical layer. On the basis of the outcomes of this research it would be possible in perspective to build a sophisticated model representing in detail the many intertwined connections between separate elements of the terminological system. Such models may be useful for analyzing the cognitive processes underlying human reasoning as well as the processes of information transmission via linguistic communication.

\section{Conclusions}

In this paper it has been shown that economic terms can be and are studied along the lines of two principal approaches - as elements of the metalanguage of a particular science and as units of communication. According to the former approach they are to meet the requirements imposed on scientific terminology in general - accuracy and exhaustiveness of a concept's description, monosemanticity, systematic character, lack of an emotional charge, brevity. At the same time economic terms serving to convey systemically structured concepts come as conventions having dual -descriptive-prescriptive meaning. This meaning duality manifests itself in the pragmatic function of the sign which is relevant for communication. This pragmatic function is determined by the following set of relationships between concepts: (1) the relations of one concept to others within the same theoretical construction, (2) the relations of a concept belonging to one theoretical system to the concepts making up an opposing theory, (3) associatively - when a certain concept being largely outside the scope of the theory is just associated with it, (4) synonymically - that's the case when two (or even more) forms come to designate the same concept usually with transparent implications due to a specific change in motivation.

\section{References}


1. M.V. Efimova, E.V. Krasnova, S.E. Marchenko, E.V. Velichko, A.K. Boiko, $3^{\text {rd }}$ International multidisciplinary scientific conference on social sciences and arts (conference proceedings) 3-1, 1035-1040 (2016).

2. D.V. Minakova, E.V. Krasnova, Molodojis sledovatel' Dona 4 (7), 141-146 (2017).

3. V.V. Il'in, Aksiologija 45-48 (2021).

4. A.A. Ivin, Aksiologija 179-187 (2021).

5. Cheing Lai Sheng, Value Inquiry Book Series 61, 1-2 (1998).

6. H.B. Mitchell, Roots of Wisdom: A Tapestry of Philosophical Traditions (2011).

7. R.Boudon, The Origin of Values: Essays in the Sociology and Philosophy of Beliefs (2013).

8. M.T. Musacchio, Affective Computing and Sentiment Analysis, Emotion, Metaphor and Terminology 7, 79-88 (2011)

9. James Ciment, ed., Booms and Busts: An Encyclopedia of Economic History from Tulipmania of the 1630s to the Global financial Crisis of the $21^{\text {st }}$ Century (2013).

10. Kateryna Kraus, Natalia Kraus, Dictionary of Economic Terms (2013).

11. L.J. De Lucca comp., Elsevier's Economics Dictionary in English, French,Spanish, Italian, Portuguese and German (2013).

12. Matthew Bishop, Economics: An A-Z Guide (2016).

13. Claire Annesley, A Political and Economic Dictionary of Western Europe (2005).

14. Thomas Piketty, Capital in the $21^{\text {st }}$ Century (2014).

15. Mark Hirschey, Eric Bentzen, Managerial Economics (2016).

16. Timothy Taylor, Journal of Economic Perspectives (2014).

17. Pedro A. Fuertes-Olivera, Sandro Nielsen, Terminology and Lexicography Research, Practice Dynamics and Terminology 16, 215-231 (2014).

18. Agnes Benassy-Quere, Benoit Coeure, Jean Pisani-Ferry, Economic Policy: Theory and Practice (2010).

19. Diana Wood, Medieval Economic Thought (2002).

20. Philippe J.Bernard, Planning in the Soviet Union (1966).

21. Alice Rayewsky, Since Perestroika 391, 34-49 (2000). 